\title{
Pengaruh penempatan PCM berbahan minyak sawit pada cooling vest terhadap penurunan heat strain ketika beraktifitas fisik di lingkungan panas
}

\author{
Titis Wijayanto, Oggie Alif Afyudin, Agasi Rizal Kurniawan Zain \\ Fakultas Teknik, Departemen Teknik Mesin dan Industri UGM \\ Jl. Grafika no 2 Yogyakarta 55281 \\ Email: twijaya@ugm.ac.id
}

\begin{abstract}
ABSTRAK
Paparan di lingkungan yang panas dan lembab ketika melakukan aktivitas fisik berpengaruh terhadap peningkatan risiko heat strain dan penurunan performansi kerja. Penggunaan cooling vest dengan Phase Change Material (PCM) yang dikenakan di bawah pakaian kerja banyak digunakan untuk mencegah risiko terjadinya heat strain dan untuk meningkatkan kinerja kerja, dan kenyamanan termal. Tujuan dari penelitian ini adalah untuk menentukan penempatan yang efektif dari PCM berbahan sawit pada cooling vest dengan meneliti efek fisiologis dan subyektifketika: (1) PCM hanya dipakai di bagian depan/dada (frontal cooling) dan (2) PCM hanya dipakai di bagian belakang/punggung (back cooling). Sepuluh pria sehat (usia 21,7 00,9 tahun) memakai rompi pendinginan dengan PCM saat melakukan aktivitas fisik di atas treadmil selama 30 menit dengan beban kerja sebesar $70 \%$ beban kerja maksimum di ruang dengan suhu udara $33^{\circ} \mathrm{C}$ dan kelembaban relatif 80\%. Dari hasil penelitian yang dilakukan dapat disimpulkan bahwa penempatan PCM di bagian belakang punggung sebagai cooling device lebih efektif dalam menurunkan risiko heat strain ketika melakukan aktivitas fisik di lingkungan panas dibandingkan dengan penempatan PCM di bagian dada.
\end{abstract}

Kata kunci: Phase Change Material, Cooling vest, Penurunan heat strain

\begin{abstract}
Exposure to hot and humid environment, combined with physical work, results in an increased risk of heat strain and a reduced working performance. Cooling vests using Phase Change Material (PCM) packs underneath the working coverall are often used to prevent heat strain, increase work performance, and possibly increase thermal comfort. The purpose of this study is to assess the effective placement of PCM packs in the cooling vest underneath the working coverall by examining the physiological and subjective effects when: (1) only the frontal part of torso is covered with PCM and (2) only the back part of torso is covered with PCM. Ten healthy males (age $21.7 \pm 0.9$ years) wore the cooling vest with PCM while performing a 30 min treadmill exercise at $70 \%$ of maximum workload in a chamber set at $33^{\circ} \mathrm{C}$ of air temperature and $80 \%$ relative humidity. From the results of this study, it can be concluded that covering the back part of torso with PCM is more effective in alleviating heat strain risk during physical activities in hot environment than covering the frontal part of torso.
\end{abstract}

Keywords: Phase change material, Cooling vest, Heat strain alleviation

\section{Pendahuluan}

Pekerja yang melakukan aktivitas kerja fisik di lingkungan kerja yang panas berisiko untuk mengalami heat strain yang dapat mempengaruhi daya tahan tubuh dan tingkat produktivitas kerja (Gao dkk [1]). Bekerja dengan tingkat metabolisme yang tinggi dalam jangka waktu yang lama juga dapat menyebabkan terjadinya elevasi pada temperatur inti tubuh dan menyebabkan terjadinya kelelahan kerja. Salah satu solusi yang dapat diterapkan untuk mengurangi terjadinya heat strain dan meningkatkan ketahanan tubuh ketika bekerja adalah dengan menggunakan cooling vest pada saat melakukan pekerjaan(Gao dkk [1]). Pada umumnya cooling vest ini dilengkapi dengan Phase Change Material (PCM) yang ditempatkan di dalam sakusaku yang ada pada cooling vest (Gao dkk [1]; Loumala dkk [2]; Hasegawa dkk [3]; Wang dkk. [4]; Gao dkk[5]).

Penggunaan cooling vest dengan menggunakan PCM berbahan gell pack, parafin, ataupun garam PCM dianggap sebagai salah satu teknik pendinginan tubuh yang efektif dalam membantu menurunkan heat strain di lingkungan yang panas (Loumala dkk [2], Hasegawa dkk [3]). Penggunaan PCM yang dipasangkan dalam cooling vest membantu pekerja untuk mengurangi heat strain ketika PCM berubah fase dari padat menjadi cair (Gao dkk[5], Shim dkk [6]). Semakin banyak PCM yang dipasangkan pada cooling vest akan meningkatkan tingkat efektivitas dari PCM untuk mendinginkan tubuh ketika beraktivitias fisik dalam durasi yang lebih lama. Akan tetapi, terdapat trade off antara jumlah PCM yang digunakan dan beban tambahan yang akan dialami oleh pekerja. Untuk itu, penelitian terkait dengan penempatan posisi PCM pada cooling vest menjadi penting, terutama hal ini akan berpengaruh terhadap efektivitas dari PCM dalam mendinginkan tubuh dan mengurangi risiko terjadinya heat strain. 
Dalam penelitian Itani dkk [7] terkait dengan penempatan PCM cooling vest disebutkan bahwa core temperature sedikit mengalami penurunan ketika mengenakan cooling vest di dada ataupun di punggung. Meskipun demikian, temperatur pada kulit pada bagian punggung dan dada menurun sebesar $5^{\circ} \mathrm{C}$ dan $3^{\circ} \mathrm{C}$ ketika PCM dipasangkan pada posisi tubuh tersebut. Selain itu, kenyamanan termal mulai dirasakan ketika PCM mulai mencair hingga akhir dari aktivitas fisik (Itani dkk [7]). Senada dengan penelitian tersebut, Reinertsen dkk. [8] melaporkan bahwa meskipun penggunaan PCM pada seluruh bagian torso dapat menjaga agar suhu kulit tetap rendah, sensasi termal dan kenyamanan termal dirasakan lebih baik ketika PCM dipasangkan hanya pada bagian depan/dada dan pada bagian punggung. Sementara itu, dari penelitian Choi dkk [9] menyebutkan bahwa penggunaan PCM untuk body cooling pada posisi dada dan punggung dapat memberikan tingkat kenyamanan yang lebih baik dibandingkan penempatan pada bagian leher dan kepala. Dari penelitian-penelitian terdahulu, dapat diketahui bahwa posisi penempatan PCM pada bagian dada atau punggung merupakan posisi yang efektif untuk menurunkan risiko heat strain. Akan tetapi, posisi penempatan PCM yang efektif menurunkan heat strain masih dalam perdebatan, apakah sebaiknya PCM ditempatkan pada bagian depan (frontal cooling) atau bagian belakang (back cooling).

Dari uraian di atas, tujuan dari penelitian ini adalah untuk menentukan penempatan yang efektif dari PCM berbahan gell pack pada cooling vest dengan meneliti efek fisiologis dan subyektif ketika: (1) PCM hanya dipakai di bagian depan/dada (frontal cooling) dan (2) PCM hanya dipakai di bagian belakang/punggung (back cooling). PCM yang digunakan dalam penelitian ini adalah PCM berbahan minyak sawit dengan titik lebur $24^{\circ} \mathrm{C}$. Pemilihan PCM berbahan minyak sawit ini dilakukan dengan mempertimbangkan ketersediaannya di Indonesia yang cukup melimpah. Selain itu, berdasarkan penelitian Gao dkk [10] yang menyebutkan bahwa PCM dengan melting point yang rendah (di atas $20^{\circ} \mathrm{C}$ ) lebih fleksibel untuk penyimpanannya dan mudah dibekukan pada suhu ruangan serta dapat memberikan efek yang lebih efektif dalam mengurangi heat strain yang dialami ketika melakukan aktivitas fisik.

\section{Metode Penelitian}

\section{Subjek Penelitian}

Subyek penelitian ini adalah mahasiswa laki-laki yang aktif berolahraga sebanyak 10 orang dengan rata-rata usia 21,72 \pm 0.90 tahun, tinggi badan 172,81 $\pm 5,51 \mathrm{~cm}$, berat badan 66,14 $\pm 8,10 \mathrm{~kg}$ dan VO2max 61,12 $\pm 5,99 \mathrm{ml} . \mathrm{kg}-1$.min-1. Seluruh subyek mengenakan working coverall (Nomex IIIA) dan perlengkapan safety seperti safety shoes dan safety helmet selama eksperimen berlangsung.

\section{Prosedur Penelitian}

Tahapan awal penelitian ini diawali dengan pengukuran beban kerja maksimum dengan berlari di treadmill menggunakan metode Bruce (Bruce et al, [11]). Subyek akan diminta melakukan aktivitas fisik menggunakan treadmill dengan kecepatan awal 2,7 km/h dan kemiringan 0\% selama 3 menit, kemudian kecepatan dan kemiringan akan dinaikan setiap 3 menit hingga subyek merasa lelah. Kecepatan dan kemiringan maksimal yang dapat dicapai oleh subjek kemudian ditetapkan sebagai sebagai beban kerja maksimum.

Tahapan selanjutnya adalah aktivitas fisik menggunakan beban kerja sebesar 70\% dari beban kerja maksimum yang telah diukur di hari sebelumnya selama 30 menit. Aktivitas fisik dilakukan di ruang terkondisi dengan temperatur udara $33^{\circ} \mathrm{C}$ dan kelembaban $80 \%$. Aktivitas fisik dilakukan setelah subjek menyesuaikan diri dengan kondisi lingkungan selama 10 menit dan data dari pengukuran 10 menit awal ini dijadikan sebagai baseline. Setelah aktivitas fisik dengan berjalan di atas treadmill selama 30 menit, subjek memasuki fase recovery selama 20 menit. Seasaat sebelum subjek melakukan aktivitas fisik, $P C M$ dipasangkan pada kantong-kantong cooling vest (1) hanya di bagian depan/dada (kondisi frontal cooling) dan (2) hanya di bagian punggung (kondisi back cooling). PCM yang digunakan merupakan PCM berbahan minyak sawit yang dibekukan dengan ukuran $7.5 \mathrm{~cm}$ x $17.5 \mathrm{~cm}$. Adapun jumlah PCM yang dipasangkan pada kondisi frontal cooling adalah sebanyak 5 buah, sedangkan pada kondisi back cooling sebanyak 5 buah PCM.

\section{Pengukuran}

Selama aktivitas fisik berlangsung dilakukan pengambilan data temperatur timpani (Tty) menggunakan sensor infrared tympanic temperature yang dipasangkan ke dalam lubang telinga subjek (Nipro CT-1, Japan) dan direkam setiap detik selama eksperimen berlangsung. Temperatur kulit diukur pada 10 titik pengukuran (dahi, dada, abdominal, punggung atas, punggung bawah, lengan bawah, punggung tangan, paha, betis, dan punggung kaki) yang direkam menggunakan termistor setiap 2 detik (LT 8A, Gram corp. Japan). Dari data temperatur kulit, mean skin temperature (mean Tskin) diestimasi menggunakan persamaan Hardy duBois. Denyut jantung menggunakan heart rate monitor (Polar RS800X, Finland) dan direkam setiap detik selama eksperimen berlangsung. Pengukuran subjektif meliputi thermal sensation (TSV) dan thermal comfort diukur setiap 10 menit menggunakan skala kenyamanan termal yang mengacu pada ISO 7730-2005.

\section{Analisis Statistika}


Data yang direkam oleh data logger dirata-rata setiap interval 5 menit untuk selanjutnya dilakukan analisis statistika. Data hasil penelitian memenuhi asumsi normalitas dan homogenitas, sehingga pengujian statistika dilakukan menggunakan repeated measures ANOVA (time x condition). Post hoc test dengan menggunakan Bonferroni correction dilakukan ketika hasil repeated measures ANOVA menunjukkan adanya perbedaan signifikan. Data disajikan dalam bentuk mean \pm standard error $(S E)$. Analisis statistika diatur pada nilai signifikansi $\mathrm{p}<0.05$.

\section{Hasil dan Pembahasan}

\section{Tympanic temperature}

Gambar 1 menampilkan data Tympanic temperature (Tty) yang telah dirata-rata setiap 5 menit untuk ketiga kondisi eksperimen, No cooling, frontal cooling, dan back cooling. Pada fase physical activity, Tty pada kondisi no cooling mengalami kenaikan paling tinggi, dibanding Tty kondisi frontal cooling ataupun back cooling. Pemasangan PCM pada bagian belakang/punggung (back cooling) mampu menahan kenaikan Tty lebih baik dibandingkan kedua kondisi lainnya. Pada menit ke-25 fase physical activity, Tty pada kondisi back cooling berada pada temperatur yang lebih rendah dibandingkan kondisi no cooling hingga akhir fase recovery berakhir. Sementara itu, Tty pada kondisi back cooling lebih rendah dibandingkan dengan kondisi frontal cooling mulai dari akhir fase physical activity hingga akhir recovery.

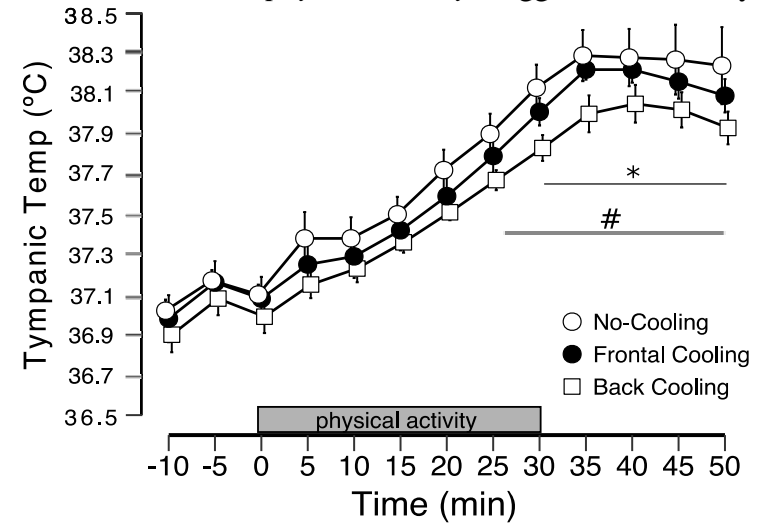

Gambar 1. Tympanic temperature pada tiga kondisi eksperimen: No.-cooling, Frontal cooling, dan Back cooling. \# menunjukkan perbedaan signifikan antara No cooling dan Back cooling $(\mathrm{p}<0.05)$;

* menunjukkan perbedaan signifikan antara Frontal cooling dan Back cooling $(\mathrm{p}<0.05)$

\section{Mean skin temperature}

Data mean skin temperature (mean Tskin) yang telah dirata-rata setiap 5 menit untuk ketiga kondisi eksperimen, No cooling, frontal cooling, dan back cooling disajikan pada Gambar 2. Pada fase physical activity, mean Tskin langsung mengalami penurunan pada kondisi frontal cooling ataupun back cooling. Perbandingan antara kedua kondisi body cooling menunjukkan bahwa penurunan mean Tskin yang signifikan terjadi pada kondisi pemasangan PCM pada bagian belakang punggung (back cooling) dibandingkan dengan pemasangan PCM pada bagian depan (frontal cooling). Hal ini menunjukkan bahwa penyerapan panas oleh PCM pada permukaan tubuh bagian belakang lebih efektif dibandingkan dengan penyerapan panas oleh PCM yang dipasang di bagian depan.

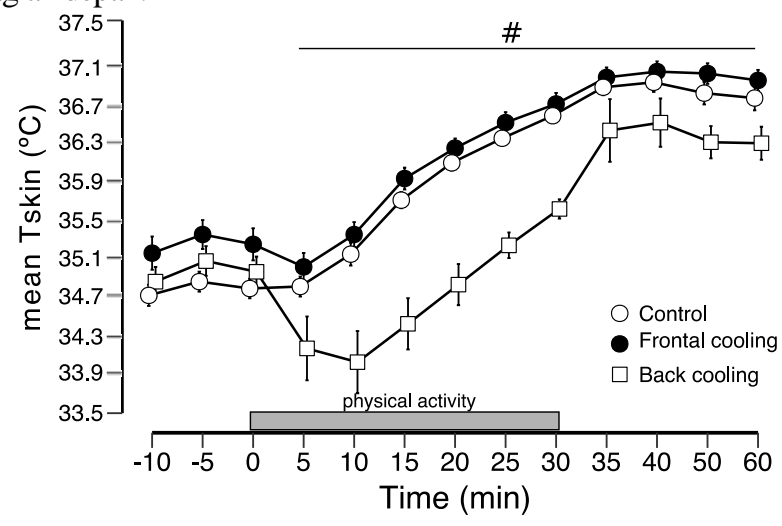

Gambar 2. Mean Tskin pada tiga kondisi eksperimen: No.-cooling, Frontal cooling, dan Back cooling. \# menunjukkan perbedaan signifikan antara No cooling/Frontal cooling dan Back cooling $(\mathrm{p}<0.05)$ 


\section{Denyutjantung}

Denyut jantung (heart rate) merupakan salah satu indikator yang banyak digunakan untuk mengukur beban kerja fisik yang dialami responden selama eksperimen. Grafik perubahan denyut jantung setiap kondisi dapat dilihat pada Gambar 3. Perubahan nilai denyut jantung relatif sama pada setiap kondisi. Pengujian statistika pada data denyut jantung menunjukkan tidak adanya ada perbedaan signifikan antar kondisi $(\mathrm{p}>0,05)$.

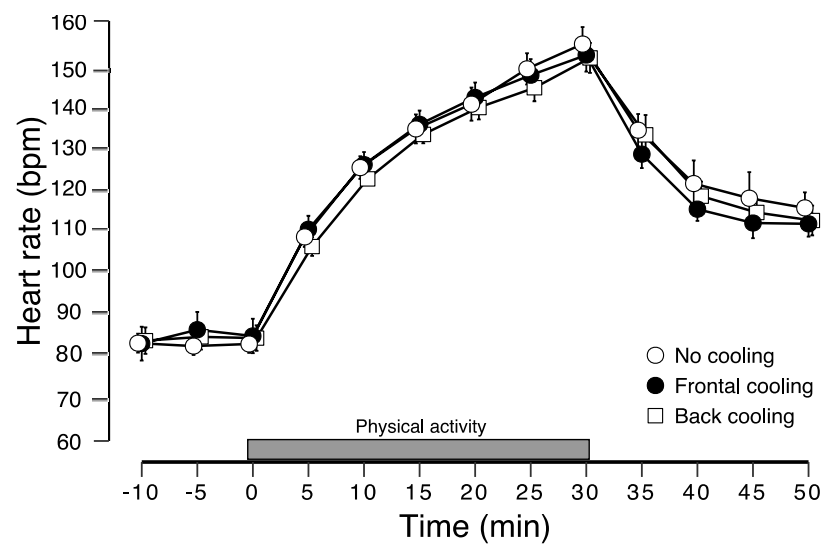

Gambar 3. Denyut jantung (Heart rate) pada tiga kondisi eksperimen: No cooling, Frontal cooling, dan Back cooling.

\section{Respon subyektif}

Thermal sensation (TSV) dan thermal comfort (TCV) merupakan indikator sensasi termal dan kenyamanan yang dirasakan responden selama eksperimen (Gambar 4). TSV naik pada fase physical workload hingga menit ke-30 seiring dengan peningkatan aktivitas fisik, mengindikasikan bahwa sensasi termal yang dirasakan selama eksperimen adalah agak panas untuk ketiga kondisi. Sebaliknya, TCV turun pada fase physical workload hingga menit ke-30 seiring dengan peningkatan aktivitas fisik, mengindikasikan bahwa kenyamanan termal yang menurun ke arah discomfort selama eksperimen berlangsung.
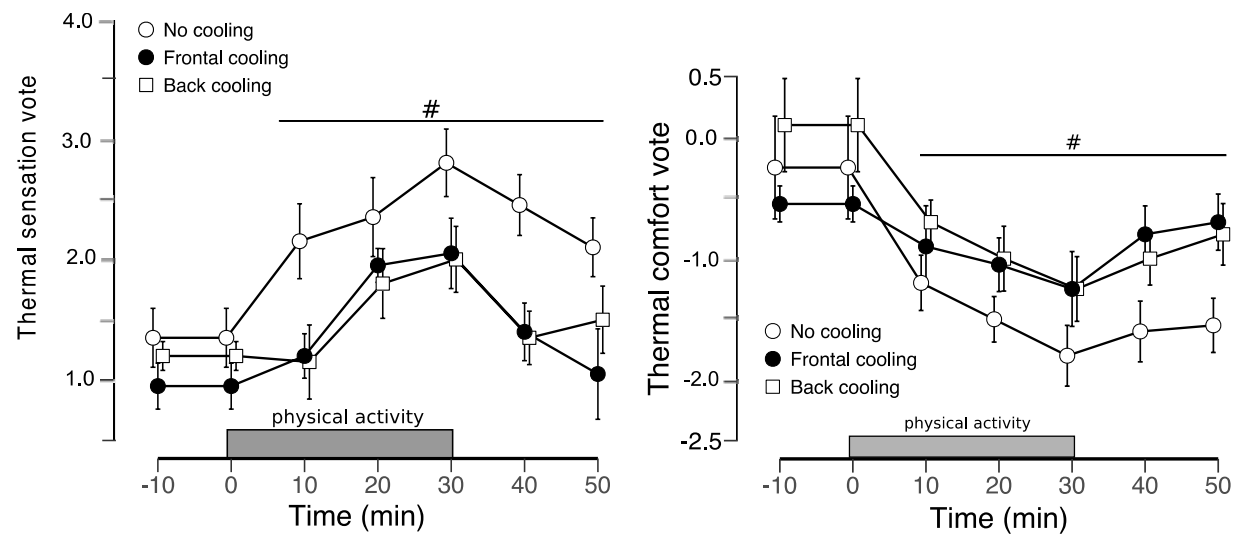

Gambar 4. Thermal sensation vote dan Thermal comfort vote pada tiga kondisi eksperimen: No cooling, Frontal cooling, dan Back cooling. \# mengindikasikan adanya perbedaan signifikan dibandingkan dengan kondisi no cooling $(\mathrm{p}<0.05)$

Pengujian statistika pada data TSV dan TCV menunjukkan ada perbedaan signifikan antar kondisi ( $<<0,05)$. Hal ini menunjukkan bahwa selama physical activity hingga recovery, kondisi yang dirasakan adalah lebih panas pada kondisi no cooling dibandingkan dengan kondisi eksperimen dengan pendinginan tubuh selama aktivitas fisik, baik dengan pemasangan PCM di depan (frontal cooling) ataupun di belakang (back cooling). Selain itu, penggunaan PCM pada cooling vest pada saat aktivitas fisik, baik di bagian depan ataupun di belakang juga memberikan kenyamanan termal yang lebih baik dibandingkan dengan tanpa pendinginan tubuh (no cooling). Perbandingan antara penempatan PCM di bagian depan dan belakang tidak menunjukkan adanya perbedaan pada TSV dan TCV antara kedua kondisi selama physical activity. 


\section{Pembahasan}

Penelitian ini bertujuan untuk mengetahui pengaruh jenis material yang digunakan sebagai PCM dan posisi penempatannya pada tubuh ketika beraktivitas fisik pada lingkungan termal $\left(33^{\circ} \mathrm{C}\right.$ dan $\left.80 \% \mathrm{RH}\right)$ terhadap penurunan risiko heat strain ditinjau dari respon fisiologis dan subyektif. Respon fisiologis yang dikaji disini adalah perubahan temperatur timpani, temperatur kulit, dan denyut jantung. Hasil penelitian menunjukkan bahwa penggunaan PCM sebagai cooling device pada saat melakukan aktivitas fisik mampu menekan laju peningkatan temperatur timpani, dan menurunkan temperatur kulit. Hal ini sesuai dengan penelitian Eijsvogels [12] yang menyatakan bahwa penggunaan cooling device mampu menurunkan respon fisiologis seperti temperatur inti tubuh, temperatur kulit, dan denyut jantung.

Terkait dengan posisi penempatan PCM di depan atau di belakang, penempatan PCM pada posisi belakang/punggung mampu menurunkan respon fisiologis yang lebih baik dibandingkan pada posisi depan/dada. Temperatur timpani yang merepresentasikan temperatur inti tubuh menunjukan bahwa peletakan PCM pada posisi belakang menghasilkan perubahan temperatur yang lebih rendah dibandingkan pada posisi depan. Selain itu, penempatan PCM pada bagian belakang mampu menurunkan temperatur kulit secara signifikan dibandingkan dengan penempatan PCM di bagian depan/dada. Hal ini menunjukkan bahwa penyerapan panas oleh PCM pada permukaan tubuh bagian belakang lebih efektif dibandingkan dengan penyerapan panas oleh PCM yang dipasang di bagian depan.

Hal ini dapat disebabkan oleh nilai konduktivitas termal dan panas pembentukan laten pada penempatan PCM di posisi belakang yang lebih tinggi $\left(10.5 \pm 2.3 \mathrm{~W} / \mathrm{m}^{2}\right)$ daripada penempatan PCM di posisi depan $\left(8.1 \pm 0.9 \mathrm{~W} / \mathrm{m}^{2}\right)$. Mehling dan Cabeza [13] menyatakan bahwa besarnya nilai konduktivitas termal dan panas pembentukan laten akan memberikan efek cooling yang besar dalam jangka waktu yang singkat. Adapun jumlah PCM yang dipasangkan pada kondisi frontal cooling adalah sebanyak 5 buah, sedangkan pada kondisi back cooling sebanyak 7 buah PCM, sehingga memungkinkan kalor yang diserap saat perubahan fase PCM dari padat ke cair jauh lebih besar pada back cooling. Akibatnya, efek pendinginan dari penempatan PCM di bagian belakang terhadap penurunan heat strain secara fisiologis menjadi lebih besar dibandingkan di bagian depan.

\section{Kesimpulan dan Saran}

Dari hasil penelitian yang dilakukan dapat disimpulkan bahwa penempatan PCM berbahan minyak sawit di bagian belakang punggung sebagai cooling device lebih efektif untuk dapat menurunkan risiko heat strain dibandingkan dengan penempatan PCM di bagian dada bila ditinjau dari respon fisiologisnya selama melakukan aktivitas fisik di lingkungan panas. Hasil ini dapat diaplikasikan untuk mencegah risiko heat strain ketika melakukan aktivitas fisik dengan durasi yang singkat (30 menit). Untuk itu, perlu dilakukan penelitian lebih lanjut untuk mengetahui efektivitas dari penggunaan PCM pada saat melakukan aktivitas fisik dengan durasi yang lebih lama.

\section{Ucapan Terima Kasih}

Penelitian ini didanai oleh hibah penelitian DTMI tahun 2015. Peneliti mengucapkan terima kasih kepada subyek yang telah berpartisipasi dalam penelitian ini

\section{Daftar Pustaka}

[1]. Gao, C., Kuklane, K., Holmer, I., Cooling vests with phase change materials: the effect of melting temperature on heat strain alleviation in an extremely hot environment, European Journal of Applied Physiology. 111 (2011) 1207-1216

[2]. Loumala, M.J., Oksa, J., Salmi, J.A., Linnamo, V., Holmer, I., Smolander, J., Dugue, B., Adding a cooling vest during cycling improves performance in a warm and humid conditions, Journal of Thermal Biology 37 (2012) 47-55

[3]. Hasegawa, H., Takatori, T., Komura, M., Yamasaki, M., Wearing a cooling jacket during exercise reduces thermal strain and improves endurance exercise performance in a warm environment, Journal of Strength and Conditioning Research. 19 (1)(2005) 122-128

[4]. Wang, F., Gao, C., Kuklane, K., Holmer, I., A review of technology of personal heating garments, International Journal of Occupational Safety and Ergonomics. 16(2010) 387-404

[5]. Gao, C., Kuklane, K., Wang, F., Holmer, I. Personal cooling with phase change materials to improve thermal comfort from a heat wave perspective. Indoor Air. 22(2012) 523-530 
[6]. H. Shim, E.A. Mccullough, B.W. JonesUsing phase change materials in clothing Text. Res. J., 71 (2001), pp. 495-502,

[7]. Itani M, Ghaddar N, Ghali K, Khater B, Ouahrani D, Chakroun W. Experimental Study on Effective Placement of PCM Packets in Cooling Vest to Improve Performance in Warm Environment. ASME. Heat Transfer Summer Conference (2017)

[8]. R.E. Reinertsen, H. Fǽrevik, K. Holbǿ, R. Nesbakken, J. Reitan, A. Røyset, M. Suong Le Thi Optimizing the performance of phase-change materials in personal protective clothing systems, Int. J. Occup. Saf. Ergon. (JOSE), 14 (1) (2008) 43-53

[9]. Choi, J.W., Kim, M.J., Lee, J.Y., Allevation of Heat Strain by Cooling Different Body Areas During Red Pepper Harvest Work at WBGT 33oC, Industrial health, 46 (2008) 620-628.

[10]. Gao, C., Kuklane, K., and Holmer, I., Cooling Vest with Phase Change Material Pack: The Effect of Temperature Gradient, Mass and Covering Area, Ergonomics, 53 (2011) 716-723.

[11]. Bruce, R.A., Kusumi, F., Hosmer, D., Maximal Oxygen Intake and Nomographic Assesment of Functional Aerobic Impairment in Cardiovascular Disease, American Heart Journal, 85 (1974) 546-562.

[12]. Eijsvogels, T.M.H., Physiological Demands of Prolonged Exercise, Radbound Universities, Netherland (2012)

[13]. Mehling, H and Cabeza, L.F., Heat and Cold Storage with PCM: An Up to date introduction into basics and applications, Springer, Berlin (2008) 